\title{
Effect of a Biofield Treatment on Plant Growth and Adaptation
}

\author{
Gopal Nayak, Nandini Altekar*
}

Trivedi foundation, 10624, S Eastern Avenue Suite A-969, Henderson, NV 89052

Received Date: July 26, 2014
Accepted Date: April 21, 2015
Published Date: April 27, 2015

*Corresponding authors: Nandini Altekar, Trivedi foundation, 10624, S Eastern Avenue Suite A-969, Henderson, NV 89052; E-mail: Publication@trivedieffect.com

Citation: Altekar, N., et al. Effect of Biofield Treatment on Plant Growth and Adaptation. (2015) J Environ Health Sci 1(2): 1-9.

Keywords: Non-contact biofield treatment; Anticancer activity; Micropropagation; Symbiotic communication; Human consciousness; Plant adaptation; Genetic impact ; Chlorophyll ; Glutathione

\section{Introduction}

Scientific methodologies were developed in order to focus on objective, reproducible phenomena, with strategies being based on the idea that material energies were distinct from biofield ones and could therefore be investigated independently. Descartes in the $17^{\text {th }}$ century was one of the first to formalize these ideas, during an era of strong pressures against scientific freedoms. They led to the development of a great deal of valuable technology able to transcend cultural differences and address major problems, providing well-defined solutions, which work reliably under the defined conditions. As the closeness of structure and function was increasingly demonstrated, there were further adjustments in this postulate, while quantum mechanics was developed when human consciousness was found to influence results at the level of elementary particles. Material and biofield energies are today more seen as capable of interaction, but with consequent effects remaining negligible under most conditions, and being sometimes explained as the mind being driven by material events. In the continuing resistance against various suggestions of external control however, these claims have now brought the concept of free will and human personal efficacy into doubt in a new way, with a suggestion that DNA manipulation may provide the most complete solution for the development of super-species. While the vital life force is accepted in the biological sciences, its nature is yet to be fully defined and understood.

The value of scientific methodology and the technology it has generated cannot be doubted and the above questions may be answered better through a study of the limits or reaches of biofield efficacy.

\begin{abstract}
Quantum mechanics was developed when human energies of consciousness were found to influence observations at the scale of elementary particles, here referred as non-contact biofield treatment or biofield energies. Quantum mechanics has also proved efficacious in biological processes. The present experiments found an enhanced and significant impact of the biofield treatment on adaptive micropropagation response and callus induction of two plant species, Withania somnifera and Amaranthus dubius. The enhancement was perhaps due to greater focus on adaptation rather than specific mechanisms, showing high potential including at biochemical and genetic levels. Possible reasons for the enhancement are discussed and a possible model is presented, consistent with current scientific theory.
\end{abstract}

There are many claims in recent times regarding the material efficacy of human biofield energy transmissions when used for healing purposes. Experiments with non-human targets however can better exclude the complications of placebo effects. A decades-long project at Princeton tested intentional energies of random humans on electronic noise in instruments and found a small impact when statistically averaged over hundreds or thousands of repetitions (Dunne and Jahn, 2005).

Data of higher significance is seen in more recent reports regarding the enhanced impact of a particular biofield energy transmission technique on inorganic and organic materials as well as on organisms, plant and animal. While biofield energies are increasingly treated as material energies within science, the results of these experiments appear to indicate the equivalence and inter-convertibility of biofield and material energies under the right conditions and characteristics, which raise the question of primary energies and free will. The Biofield energy transmissions are described (Trivedi \& Tallapragada 2008; Dabhade et al. 2009; Trivedi \& Tallapragada 2009) as having produced measurable alterations at atomic and molecular levels on crystallite structures and properties of organic and inorganic materials in powder form, which continued to develop (Trivedi et al. 2013) over a study of 140 days following a single transmission. Changes seen at the nuclear level in materials have been explained by Trivedi and Tallapragada (2009) \& by Trivedi et al. (2014) as being produced by weak interactions due to exchange of neutrinos rather than electromagnetic interactions.

An information bearing intentional biofield energy of this kind may be expected to have more meaningful impact on biological samples. The vital force is measured in biology in terms of its all-round effect on multiple independent parameters

Copy rights: (C2015 Altekar, N. This is an Open access article distributed under the terms of Creative Commons Attribution 4.0 
of organismic expression and the organism's adaptability in an environment of stress. The direct impact of a vital energy is thus objectively measurable through its influence on the self-expression of the target organism. Tests performed in vitro and in vivo proved consistent in terms of the final outcome. Additional tests showed significant increase in Patchouli plant regeneration (Patil et al. 2012). The energy has been termed the 'biofield' in these papers following the hypothesis (Rubik 2002) of an information-bearing biofield, consisting of multiple energies including but not necessarily confined to the electromagnetic, associated with living organisms and able to affect their self-regulation processes. An in-vivo study on soyabean crops conducted at Iowa State University (Lenssen 2013) shows improvement in weed control but variability in other parameters, further with a possibility of Biofield treatment being a suitable replacement for seed fungicide application. In all the above, variability is still high, especially at intermediate stages. At Pacific Ag, however, randomised in-vivo blind trials showed comparable performances between organically grown biofield-treated lettuce and tomato crops, in absence of fertilizers or pesticides, and untreated controls grown with the application of these chemicals, with a significant synergistic improvement in performance when crops were given both the biofield as well as the chemical treatment (Shinde et al. 2012). In a similar experiment, Biofield treatment gave rise to increased yield quantity and quality when it was applied to Ginseng and Organic Blueberry crops (Sances et al. 2013). In each case above the end results proved consistent with the information content of the transmission. In various in-vitro experiments (Trivedi et al. 2008 , Trivedi et al. 2009), the said Biofield treatment gave rise to changes in the multiple antibiotic sensitivity patterns along with changes in the biochemical reactions further causing the altered biotype number of the particular bacteria's .

The interaction of a plant with its environment involves complex responses based on finely controlled intra-organismic and inter-organismic communication mechanisms involving sign recognition. Inter-species communication mechanisms can extend up to recognition of signals from an altogether different kind of species, including symbiotic and parasitic interactions between plant and non-plant species such as bacteria, fungi, insects and also larger animals. Many unities of mechanisms are seen across plants and animals, including use of analogous or identical biomolecules in signalling processes. Responses to a single biochemical often differ within a plant depending on context, environment, and location, while plants are today seen as displaying complexities of problem-solving behaviour on a scale similar to that of animals, such as success in competitive and cooperative strategy, adaptation to diverse environments and communication.

Although human consciousness was found to affect results in the case of elementary particles, quantum mechanical effects were earlier believed to be insignificant or dissipated in biological systems. However their relevance within biological processes has been confirmed in photosynthesis and migration of birds (Engel et al. 2007; Gauger et al. 2009), and they are known to have significant roles in sensory receptors, which in fact have been proved to have sensitivities up to the level of single quanta (Van der Velden 1946; Turin 1996; Brookes et al. 2007). There have now been many speculations regarding mechanisms by which quantum effects may remain relevant in biolog- ical systems (e.g. review in Arndt et al. 2009). From the time of its first formulation, there have also been theoretical models of human consciousness based on quantum mechanics, partly due to some apparently mind-like properties seen in the properties of quantum mechanics.

Henry Stapp (2007) has gone further to argue that in fact the human brain and consciousness have actually arisen through selection by evolutionary forces to remain in touch with information at the quantal level of the universe, to make use of mechanisms and effects at this level and to amplify self-selected data of relevance to drive and control responses throughout the organism. Such information-focus of life is borne out by experiments and is consistent with Schrödinger's statement (1944) that processes of life are distinguished by being 'negentropic' in nature, causing an increase in order and information over time as against the increase in disorder normally seen in non-living materials by the third law of thermodynamics.

A vitalizing interaction may yield a better correlation when the test focuses mainly on adaptability rather than on specific mechanisms. We tested the biofield impact on the micropropagation response and callus induction of two plant species, namely Withania somnifera (WS) and Amaranthus dubius (AD), placed at a remote location with no contact between source and targets. To look for changes in adaptation responses, we tested morphogenetic potential in presence and absence of plant growth regulators (PGR) in basal medium, whose concentrations had been standardized for optimum response and growth of controls.

Control and treated cultures of the two species, WS and $\mathrm{AD}$, were compared for micropropagation initiation in nodal explants and callus induction from leaf explants on basal medium with and without addition of PGR. Due to the positive results seen throughout during micropropagation initiation, a second set of WS cultures was also started, which was treated after the initiation stage and studied during further stages of multiplication, regeneration and hardening, with biochemical tests being conducted on the hardened plants. Treated WS seeds were also planted alongside controls in neighbouring pots, with both being maintained in similar soil, light and aerobiology conditions for growth and biochemical observations in vivo.

To determine the scope and consistency of the impact, biochemical assays were performed for some active components in WS. The rapid maturation and improved immunity seen in treated plants were accompanied by a darker green colour of leaves and shoots. Therefore samples were compared for chlorophyll content to get a preliminary indication of quantitative and qualitative changes in photosynthetic pathways, which may underlie the apparent increase in available energy. Levels of glutathione have been shown to correlate with adaptive responses of plants, their tolerance of biotic and abiotic environmental stresses and of foreign substances or xenobiotics. Glutathione was evaluated as a biochemical marker for plant immunity and adaptability levels.

WS is an important plant in Ayurvedic medicine for its many medicinal properties, with a great deal of recent research being focused on its secondary metabolites, the withanolides, shown to be involved in a wide range of pharmacological activities including anticancer abilities. Important metabolites identified in WS leaves for their anticancer activity include Withaferin A and Withanolide D (e.g. Mir 2012; Szarc vel Szic 2014). These secondary metabolites are believed to have roles in plant 
defence, and are also proposed to be involved in adaptive mechanisms within the plant. WS is however known to show a great deal of genetic variability in the wild, with only a few phenotypes proving safe for medicinal applications. Demand for the medicinal plants reduces the sustainable supply through a combination of factors such as over-collecting, unsustainable agriculture practices, urbanization, pollution and climate change; in addition these secondary metabolites are produced only in small quantities by the plant. It was expected that any improvement in plant vital characteristics such as immunity and adaptation are likely to lead to an enhancement of the anticancer medicinal properties of the plant and availability of the commercially useful secondary metabolites. Therefore tests were also conducted for changes in levels of commercially useful secondary metabolites and in WS medicinal effects.

Plants are well known to exhibit a high degree of phenotypic plasticity in response to environmental conditions, with a capacity for change in DNA in adaptive responses. Along with change in growth parameters, morphological changes were also seen in treated plants, indicating the possibility of changes at genetic levels. DNA fingerprinting using RAPD analysis with five primers was carried out on multiple control and treated samples, DNA profiles being compared separately within each of the control and treated groups and across the two groups.

The results in the current experiments indicate their nature and warrant further experimentation to clarifying transmission processes and processes underlying results. A model is necessary for more meaningful investigations and a preliminary model is proposed here below regarding the nature of the biofield at a basic level, consistent with current scientific theory.

While the consistency of trends reported across multiple studies indicate the efficacy of the interaction due to non-contact Biofield treatment, the unexpected improvements seen in the present case, including in all variations and different kinds of repetitions conducted, demonstrate its high potential under the right conditions.

\section{Materials and Methods}

Two species, WS and AD, were monitored in initiation stages of micropropagation and WS was selected for analysis at further stages of plant growth in vivo and in vitro and in biochemical testing as described above.

\section{Cultures}

(i) Disease-free wild plants of WS and AD were screened for a high yielding variety and selected plants were grown under laboratory conditions as mother plants. Nodal and leaf explants were prepared from young shoots of the mother plants. The explants were treated with $70 \%$ ethanol, rinsed 4 times in distilled water, then surface sterilized with $0.1 \% \mathrm{HgCl}_{2}$ for $4-6 \mathrm{~min}$ and inoculated on sterilized MS basal medium (Murashige and Skoog 1962) prepared with additives as follows: For shoot induction on media with plant growth regulators (PGR), MS medium was supplemented with Benzyladenine (BAP, $1 \mathrm{mg} / \mathrm{l}$ ), Kinetin (3 $\mathrm{mg} / \mathrm{l}$ ) and $2-3 \% \mathrm{w} / \mathrm{v}$ sucrose. $\mathrm{pH}$ was adjusted to $5.8 \mathrm{using} 0.1 \mathrm{~N}$ $\mathrm{NaOH}$ and $\mathrm{HCl}$. Agar of $0.8 \% \mathrm{w} / \mathrm{v}$ was added and dissolved by heating at $80^{\circ} \mathrm{C}$ in water bath and the medium sterilized by autoclaving at $121^{\circ} \mathrm{C}, 15 \mathrm{lbs}$ pressure for 20 minutes. Cultures were incubated at $24 \pm 2{ }^{\circ} \mathrm{C}$ under cool white florescent light (quantum flux density of $40 \mu \mathrm{mol} \mathrm{m} \mathrm{m}^{-2} \mathrm{~s}^{-1}$ ) with $16 / 8 \mathrm{~h}$ photoperiod. For tests without PGR, the medium was prepared as above without the hormones. For callus formation, MS medium was supplemented with 2,4-D (2mg/l) and Benzyladenine (1mg/l).

(ii) For further testing, a second group of WS cultures similar to the above were inoculated into fresh media and treated after four weeks of incubation. These were subcultured for two weeks on fresh MS medium with optimal concentration of cytokinin for shoot multiplication and elongation. Single shoots obtained from the subculture were transferred to medium for rooting consisting of half strength or full strength MS medium supplemented with different concentrations of IBA $\left(0.5-2.0 \mathrm{mg} \mathrm{l}^{-1}\right)$. Plantlets were transferred to paper cups for hardening, leaves were harvested, washed with distilled water and used in biochemical tests described below.

All analyses of control and treated samples were conducted in duplicate with 25 replicates per set, arranged in randomized design. Nodal explant cultures were observed for percent micropropagation response, time to shoot induction, shoot lengths and number of shoots per nodal explant. Leaf explants were observed for time to callus induction and quality of calli. Results were analysed using the unpaired Student's t-test with two tails.

\section{Treatment}

Biofield Treatment was directed simultaneously at a group of culture tubes, for approximately three minutes each at the beginning of the initiation phase in the first case above and before the multiplication phase as explained in the second.

\section{Seeds}

Ten each of treated and control wild plant WS seeds were planted in adjacent pots with similar light, environment and soil conditions. These were observed for morphogenesis and growth characteristics. Leaves from the mature plant were subjected to biochemical analysis as below.

\section{Bioactivity tests and assays of active components}

The following were performed on samples from both in vivo control and treated plants and in vitro groups of control and treated plants grown in presence and absence of PGR:

Chlorophyll and glutathione. All assays were conducted in duplicate. Chlorophyll was extracted from leaf discs from each group of plants, in vivo and in vitro, and assayed by spectrophotometer according to the method of Arnon (1949). Glutathione (GSH) was assayed using fresh leaves according to the method of Moron et a1. (1979).

WS anticancer activity was tested using the MTT assay (3-(4,5-dimethylthiazol-2-yl)-2,5-diphenyltetrazolium bromide assay) according to the method of Kang et al. (2004) to determine the viability of cells from the human hepatocellular liver carcinoma cell line, HepG2, when grown in presence of WS extracts from samples from each of the in vivo and in vitro groups described above. Each assay was conducted in triplicate. Cytotoxicity was tested for three different concentrations of WS extracts from each sample to confirm a dose response. After screening WS extracts in hexane, ethyl acetate, chloroform and methane for anti-cancer toxicity, ethyl acetate extract was selected for the best dose response and lowest concentration of 
extract for $\mathrm{IC}_{50}$, the concentration resulting in a $50 \%$ decrease in the control level of proliferation of HepG2 cells. Ethyl acetate extracts of WS are known to contain all major metabolites of WS, and were used in concentrations of $1000 \mu \mathrm{g} / \mathrm{ml}, 500 \mu \mathrm{g} / \mathrm{ml}$ and $100 \mu \mathrm{g} / \mathrm{ml}$. In addition to extracts from treated and untreated WS extract, two further treatments were tested, namely cell viability in absence of any of these additives ('No drug', calibrated as zero toxicity i.e. baseline or $100 \%$ viability), and cell viability in presence of the anti-cancer drug, cyclophosphamide, used as a positive control. Both control tests were repeated separately in each series while testing extracts of treated WS and extracts of untreated WS, and gave identical results each time. The mean of the cell viability values in each case was compared to determine the effect of the treatment and \% cell viability was plotted against concentration of the plant extract. $\mathrm{IC}_{50}$ was determined to be less than $1000 \mu \mathrm{g} / \mathrm{ml}$ of untreated WS extract.

Further details of the MTT assay are as follows: Liver cancer cells were grown in a 96-well plate in Delbucco's minimum essential medium (DMEM) supplemented with $10 \%$ fetal bovine serum and antibiotics (streptomycin, penicillin-G, kanamycin, amphotericin B) to remove contamination. About 1 $\mathrm{ml}$ cell suspension $(105$ cells $/ \mathrm{ml})$ was seeded in each well and incubated at $370^{\circ} \mathrm{C}$ for 48 hours in $5 \% \mathrm{CO}_{2}$ for formation of $100 \%$ confluent monolayer. Monolayer cells thus formed were exposed separately to the treatments outlined above. The cell viability was measured using MTT $(5 \mathrm{mg} / \mathrm{mL})$ and DMSO. The salt is metabolically reduced by viable cells to yield a blue insoluble Formosan product, which was measured at $570 \mathrm{~nm}$ on spectrophotometer.

Withaferin A and Withanolide D content. As these WS secondary metabolites are known to be major active components in its anticancer activity, their levels were determined by extracting $1 \mathrm{gm}$ tissue from each group of samples in vivo and in vitro, using methanol 3 times as a complete polar solvent, and analysing the extract by High-performance liquid chromatography (HPLC).

DNA polymorphism. DNA was extracted from leaves of five control plants (C1-C5) and five treated plants (T1-T5) from each of the control and treated in vivo and in vitro groups, using the method of Doyle and Doyle (1990), slightly modified by adding $0.2 \%$ polyvinylpyrrolidone to the cetyltrimethyl ammonium bromide (CTAB) extraction buffer to prevent co-isolation of phenolics and polysaccharides. Purity of extracted DNA was confirmed by spectrophotometer.

DNA profiles generated by RAPD analysis were compared for genetic variations within and across control and treated groups. Primers selected after screening for reproducibility were as follows: for in vivo samples, five primers, namely, OPA 9, OPA 10, OPB 4, OPB 12 \& OPC 7, for in vitro samples, three, namely OPA 7, OPA $9 \&$ OPB 4. The total reaction mixture of $20 \mu \mathrm{l}$ contained $2.0 \mu \mathrm{l} 1 \mathrm{X}$ Assay Buffer, $0.2 \mathrm{mM}$ dNTPs, $2.5 \mathrm{mM}$ $\mathrm{MgCl}_{2}, 0.4 \mu \mathrm{M}$ primer, $50 \mathrm{ng}$ DNA and 2.5U of Taq Polymerase. PCR amplification was carried out in an Eppendorf Master Cycler Personnel Thermocycler programmed to 1 cycle at $94^{\circ} \mathrm{C}$ for 3 minutes for initial denaturation, followed by 39 cycles of denaturation at $94^{\circ} \mathrm{C}$ for 30 seconds, annealing at $37^{\circ} \mathrm{C}$ for 1 minute, extension at $72^{\circ} \mathrm{C}$ for 2 minutes, one cycle of final extension at $72^{\circ} \mathrm{C}$ for 10 minutes and hold at $4^{\circ} \mathrm{C}$. Results were analysed using Popgene software for genetic analysis.

\section{Statistical analyses}

Results were analysed for significance using GraphPad QuickCalcs software to apply the unpaired Student's t-test with two tails. The number of replicates is indicated in each table and figure.

\section{Results}

\section{Plant growth}

Results were highly consistent across all the species and tests. While control plants showed a reduced performance in absence of PGR (Figure 1, Supplementary Table S1), treated plants showed a far reduced impact of PGR-deprivation. In all cases, treated plants in vitro with or without PGR showed a tendency to early germination and quick maturing of plants indicative of high vitality. WS plants, which were treated at later stages and tested through further multiplication stages showed early tendency to rooting during the multiplication stage itself. Plants which received both biofield treatment and PGR supplements showed the best performance in most cases indicating that an improved environment was synergistic with the vitality treatment and the combination of both proved the most beneficial. However, AD treated plants in absence of PGR significantly outperformed other corresponding sets in number of shoots and mean shoot lengths; indicating that improved vitality in presence of adaptive challenge can also sometimes produce a large response.

Table S1. Micropropagation response and callus induction during initiation, on media with and without plant growth regulator (PGR).

\begin{tabular}{|c|c|c|c|c|c|c|c|}
\hline \multirow{2}{*}{$\begin{array}{l}\text { Set } \\
(n=25)\end{array}$} & \multirow{2}{*}{$\begin{array}{l}\text { Res- } \\
\text { po } \\
\text { nse } \\
\%\end{array}$} & \multicolumn{2}{|l|}{ Shoot } & \multirow{2}{*}{$\begin{array}{l}\begin{array}{l}\text { No of } \\
\text { shoots } \\
\text { per } \\
\text { explant }\end{array} \\
\begin{array}{l}\text { Mean } \pm \\
\text { SD }\end{array}\end{array}$} & \multirow{2}{*}{$\begin{array}{l}\text { Shot } \\
\text { len } \\
\text { gth in } \\
\mathrm{cm}\end{array}$} & \multirow[b]{2}{*}{$\%$} & \multirow{2}{*}{$\begin{array}{l}\text { Callus } \\
\text { re- } \\
\text { sponse }\end{array}$} \\
\hline & & $\begin{array}{l}\text { D a y s } \\
\text { to in- } \\
\text { duction }\end{array}$ & $\begin{array}{l}\text { D a y s } \\
\text { to ma- } \\
\text { turity }\end{array}$ & & & & \\
\hline \multicolumn{8}{|l|}{$\begin{array}{l}\text { W i t h a n i a } \\
\text { somnifera }\end{array}$} \\
\hline $\begin{array}{l}\text { W i t h o u t } \\
\text { PGR, control }\end{array}$ & 10 & 15 & 30 & $\begin{array}{l}0.5 \pm \\
0.1\end{array}$ & $\begin{array}{l}1.2 \pm \\
0.2\end{array}$ & 0 & - \\
\hline $\begin{array}{l}\text { W i t h o u t } \\
\text { PGR, treated }\end{array}$ & 50 & 10 & 21 & $\begin{array}{l}2.6 \pm \\
0.1 * *\end{array}$ & $\begin{array}{l}3.5 \pm \\
0.4^{* *}\end{array}$ & 60 & 10 \\
\hline $\begin{array}{l}\text { With PGR, } \\
\text { control }\end{array}$ & 70 & 15 & 28 & $\begin{array}{l}2.4 \pm \\
0.5\end{array}$ & $\begin{array}{l}4.5 \pm \\
0.6\end{array}$ & 55 & 15 \\
\hline $\begin{array}{l}\text { With PGR, } \\
\text { treated }\end{array}$ & 70 & 12 & 28 & $\begin{array}{l}2.8 \pm \\
0.2 *\end{array}$ & $\begin{array}{l}4.2 \pm \\
0.6\end{array}$ & 83 & 10 \\
\hline \multicolumn{8}{|l|}{$\begin{array}{l}\text { Amaranthus } \\
\text { dubius }\end{array}$} \\
\hline $\begin{array}{l}\text { W i t h o u t } \\
\text { PGR, control }\end{array}$ & 5 & 20 & 30 & $\begin{array}{l}1.2 \pm \\
0.8\end{array}$ & $\begin{array}{l}1.5 \pm \\
0.2^{2}\end{array}$ & 0 & - \\
\hline $\begin{array}{l}\text { W i t h o u t } \\
\text { PGR, treated }\end{array}$ & 60 & 10 & 21 & $\begin{array}{l}3.0 \pm \\
0.1 * *\end{array}$ & $\begin{array}{l}3.5 \pm \\
0.4^{* *}\end{array}$ & 0 & - \\
\hline $\begin{array}{l}\text { With PGR, } \\
\text { control }\end{array}$ & 50 & 12 & 28 & $\begin{array}{l}2.4 \pm \\
0.3\end{array}$ & $\begin{array}{l}3.2 \pm \\
0.6\end{array}$ & 0 & - \\
\hline $\begin{array}{l}\text { With PGR, } \\
\text { treated }\end{array}$ & 78 & 12 & 28 & $\begin{array}{l}2.6 \pm \\
0.04^{*}\end{array}$ & $\begin{array}{l}3.0 \pm \\
0.3\end{array}$ & 0 & - \\
\hline
\end{tabular}

$* \mathrm{p} \leq 0.0005 ; * * \mathrm{p}<0.0001$ 


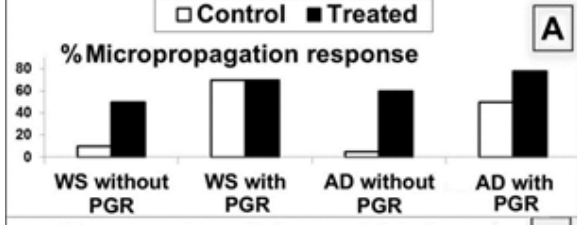

Mean number of shoots, initiation
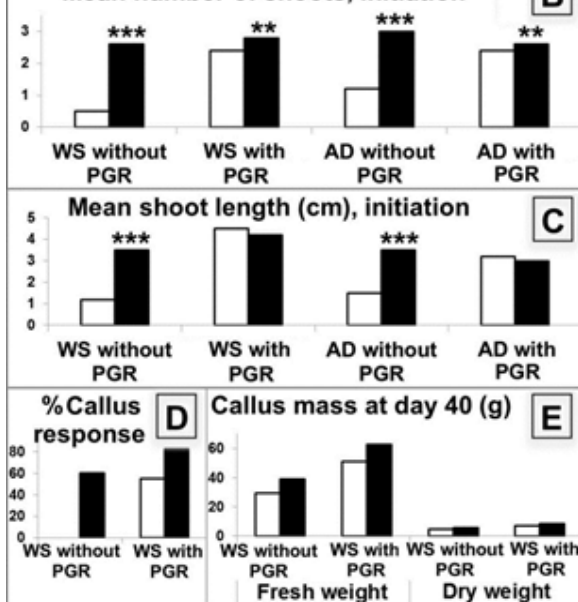

Figure 1. Micropropagation initiation in control and biofield treated Withania somnifera (WS) and Amaranthus dubius (AD) in absence and presence of plant growth regulators (PGR). Asterisks indicate significant results. ( $* *: p \leq 0.0005$; $* * *: \mathrm{p}<0.0001, \mathrm{n}=25$ each in two replicates)

Morphological differences were also visible at early stages (Figure 2, Figure 3), treated plants in presence or absence of PGR showing tendencies to thick short shoots with multiple shoots proliferation of more than 2-3 shoots per culture whereas controls had longer mean shoot length when allowed to develop normally in presence of PGR. Leaves were broader on treated plants and the plants had a darker green colouring of a different shade of green. The differences are graphically evident in Figure 1 while progressive differences in parameters over time are presented in Figure 4; most trends became significant by the $30^{\text {th }}$ day. WS callus induction also showed indications of increase in vitality (Figure $1 \mathrm{D}$, Figure 5, Supplementary Table S1). No callus induction was observed in $\mathrm{AD}$, either treated or control.

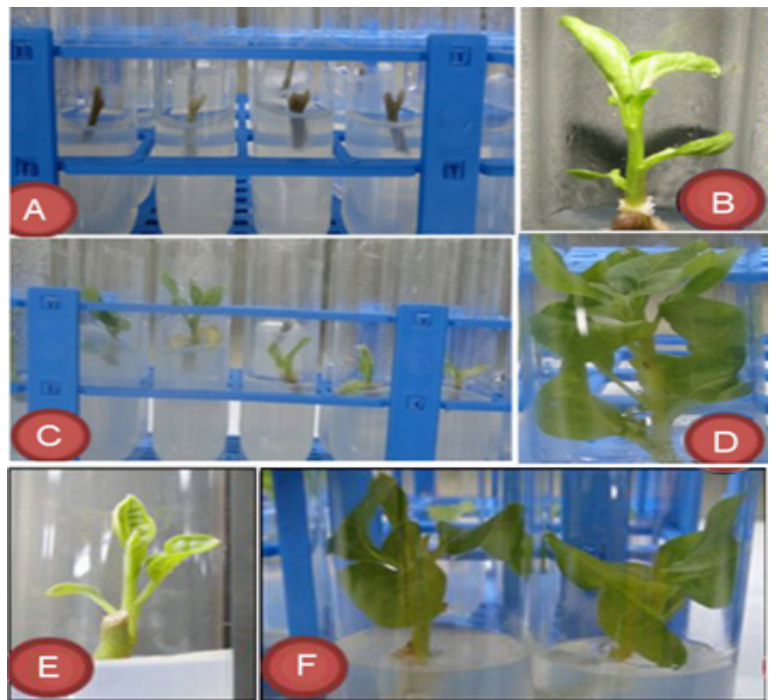

Figure 2: Micropropagation of WS. (A, B) Controls, (A) without PGR and (B) with PGR. (C, D) Treated, (C) without PGR, (D) with PGR. (E, F) without PGR at six weeks, control \& treated, respectively, with (E) at higher magnification. Differences were seen in growth parameters and morphology.

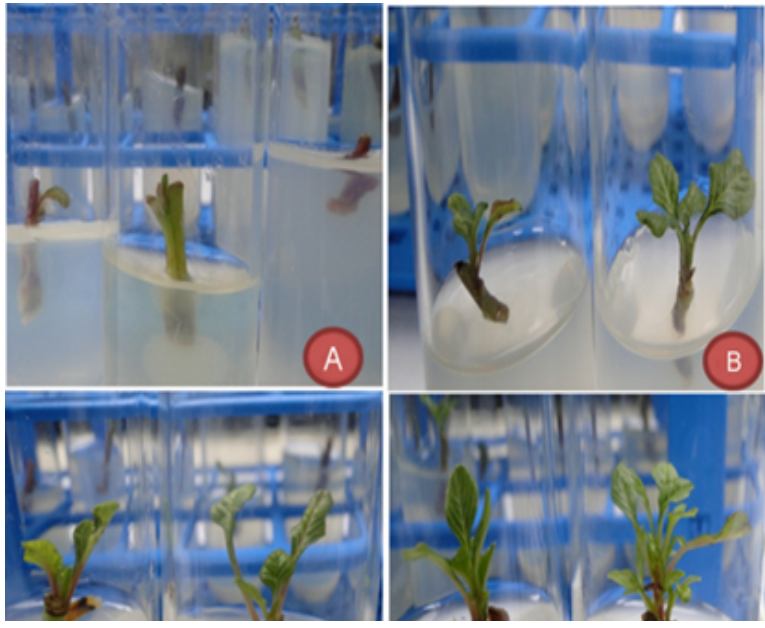

Figure 3. Micropropagation of AD. (A, B) Without PGR, control \& treated respectively. (C, D) With PGR, control \& treated respectively.

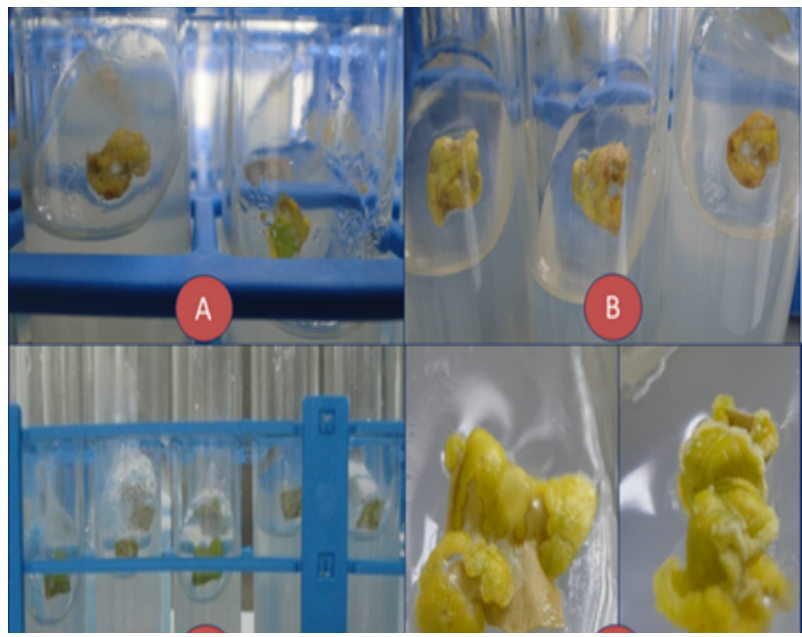

Figure 4: Callus initiation of WS leaf explants. (A, B) Without PGR, control $\&$ treated respectively. (C, D) With PGR, control \& treated respectively, (D) at higher magnification.

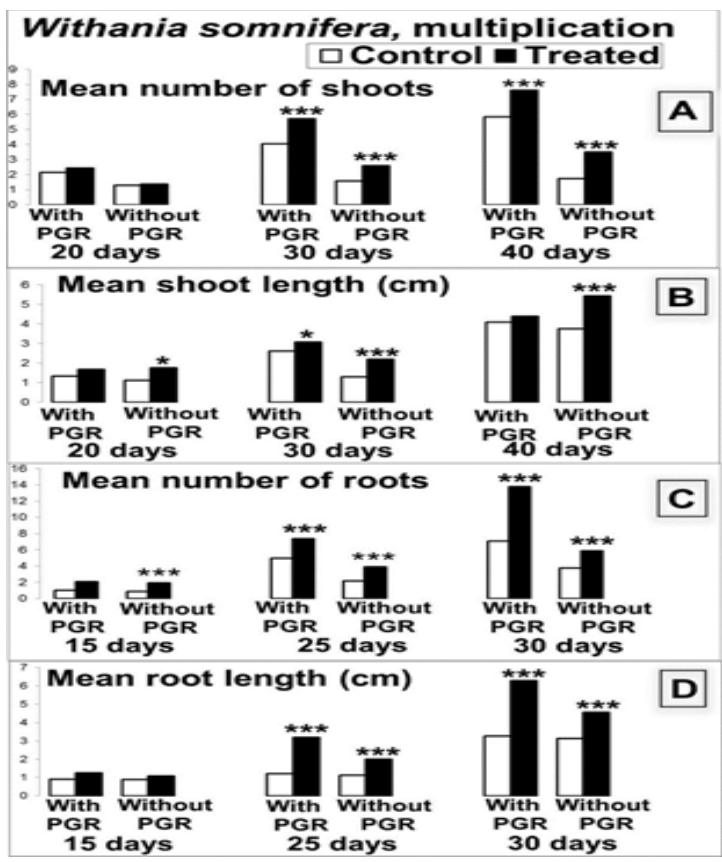

Figure 5: Comparative responses of control and treated WS during multiplication and rooting in presence and absence of PGR at progressive stages. Asterisks indicate significant results. $(*: \mathrm{p}<0.05 ; * *$ : $\mathrm{p} \leq 0.0005 ; * * *: \mathrm{p}<0.0001, \mathrm{n}=25$ each in two replicates) 
Control and treated WS wild plant seeds, planted in neighbouring pots with similar soil, light and aerobiology conditions also gave similar results. Thus the impact of the treatment remained consistent in the current case over repetitions in different types of tests. In vivo plants resulting from treated seeds showed rapid maturing rates, morphological differences similar to the above and increased immunity and yield (Figure 6, Table 1). Thus a gain in vitality was seen in treated plants throughout. Assays were therefore conducted for levels of relevant active components.

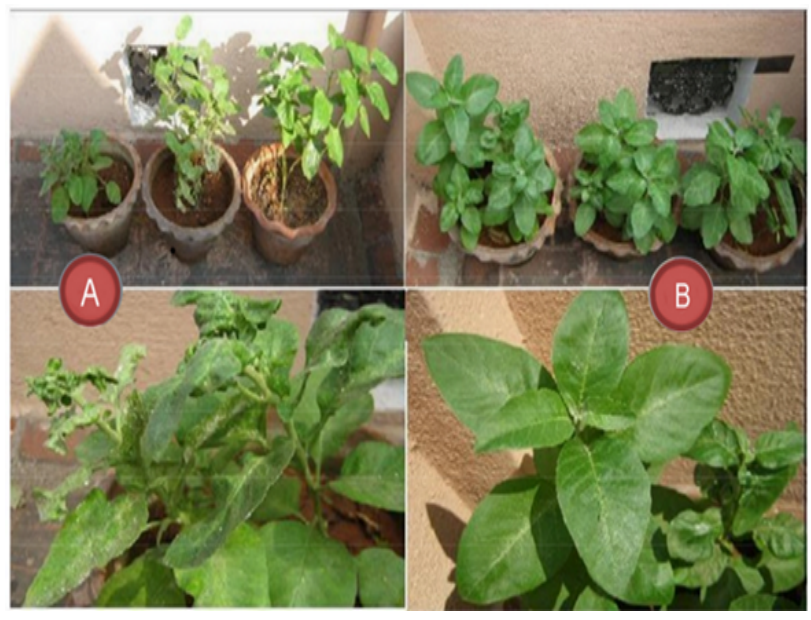

Figure 6: WS, in vivo, from control and treated seeds. (A) Controls. (B) Treated, showing increased vitality and change in morphology. in reaction centres, when their concentrations were increased. Hence further investigations are necessary to fully understand the details of the alterations.

Chlorophyll a:b ratios lie between 2 to 3 in most plants. In shade-adapted plants however, these ratios decrease in a majority of plants in order to cover a larger range of wavelengths of incident light as the absorption peaks of chlorophyll $b$ cover a different set of wavelengths including more of the intermediate regions of visible light. The ratio of the two photosystems, PSI and PSII, also changes towards more efficient processes in shade-adapted systems. As much of the light energy absorbed by PSII is eventually used by PSI for storage in chemical bonds, the ratio of these systems can greatly affect the efficiency of photosynthesis and the need for additional quenching processes to dissipate excess light absorption.

Thus decrease in the chlorophyll a:b ratio alone is not a sufficient indicator of whether efficiency of processes has increased or decreased, and the necessary direction of change in chlorophyll depends on the precise operating point of the process. In control plants in the current case, chlorophyll a:b ratios were found to be on the low side, close to 1.5 , indicating the probable operation of shade-adapted systems. The results confirm a change at the biochemical level in photosynthetic pathways and when coupled with the morphological observations and the data regarding the growth of the plants suggest that the changes are likely to be a shift towards processes of higher efficiency, perhaps similar to the processes in conditions of shade.

Table 1. Comparison of WS wild plant growth in vivo

\begin{tabular}{|c|c|c|c|c|c|c|c|c|c|}
\hline & Whole Plant & & Leaf & & Stem & Flower & & $\begin{array}{c}\text { Seed } \\
\text { Setting }\end{array}$ & Immunity \\
\hline Control & $\begin{array}{l}\text { Long, slender, } \\
\text { less foliage }\end{array}$ & $\begin{array}{c}\text { Narrow and small leaf } \\
\text { pattern }\end{array}$ & $\begin{array}{l}\text { Less clustering of } \\
\text { leaves }\end{array}$ & $\begin{array}{l}\text { Pale } \\
\text { green in } \\
\text { color }\end{array}$ & $\begin{array}{l}\text { Long and } \\
\text { slender }\end{array}$ & $\begin{array}{l}\text { 7th month } \\
\text { from Day of } \\
\text { Treatment) }\end{array}$ & $\begin{array}{l}40 \% \\
\text { Flow- } \\
\text { ering }\end{array}$ & $\begin{array}{c}30 \% \\
\text { Seed } \\
\text { setting }\end{array}$ & $\begin{array}{c}7 \text { of } 10 \text { plants with } \\
\text { signs of pest attack, } \\
\text { deformations and } \\
\text { wrinkles }\end{array}$ \\
\hline Treated & $\begin{array}{l}\text { Short and } \\
\text { healthy, more } \\
\text { foliage }\end{array}$ & $\begin{array}{l}\text { Broader, well-formed } \\
\text { leaves with glossy } \\
\text { appearance }\end{array}$ & $\begin{array}{l}\text { Larger leaf clusters } \\
\text { with greater num- } \\
\text { bers of leaves }\end{array}$ & $\begin{array}{l}\text { Dark } \\
\text { green in } \\
\text { color }\end{array}$ & $\begin{array}{l}\text { Thick } \\
\text { and } \\
\text { stronger }\end{array}$ & $\begin{array}{l}\text { 5th month } \\
\text { after Day of } \\
\text { Treatment }\end{array}$ & $\begin{array}{l}85 \% \\
\text { Flow- } \\
\text { ering }\end{array}$ & $\begin{array}{c}70 \% \\
\text { Seed } \\
\text { setting }\end{array}$ & $\begin{array}{c}\text { Tip portion of one } \\
\text { plant showed signs of } \\
\text { pest attack }\end{array}$ \\
\hline
\end{tabular}

\section{Chlorophyll and glutathione}

The differences seen in the colours of treated plants indicated a change in pigmentation, while the apparent increase in available energy pointed to a possibility of change in photosynthetic pathways. The major plant pigments are chlorophyll $a$, chlorophyll $b$ and carotenoids. Of these the first two were measured in these preliminary studies, to quantitatively confirm the scope and consistency of the effect at biochemical levels. Concentrations of chlorophyll $\mathrm{a}$, chlorophyll $\mathrm{b}$ and total chlorophyll were consistently higher in treated plants (Figure 7 A-C), and statistically higher in WS plants in vivo as well as in vitro in absence of PGR (significance marked in the figures). Increase was more in chlorophyll $b$ than chlorophyll a, being nearly twice as much in vivo and in cultures grown without PGR. Thus there was up to twofold change in ratio of chlorophyll $a: b$ from higher chlorophyll a content to higher chlorophyll b content.

Chlorophyll a is normally found to be more abundant in plants, with the majority of the chlorophyll $b$ being used in the antenna units of Photosystem II (PSII) and the reaction centres of both photosystems (PSI and PSII) being forms of chlorophyll a, P700 and P680 respectively. However there have been instances when other types of chlorophylls have also been used

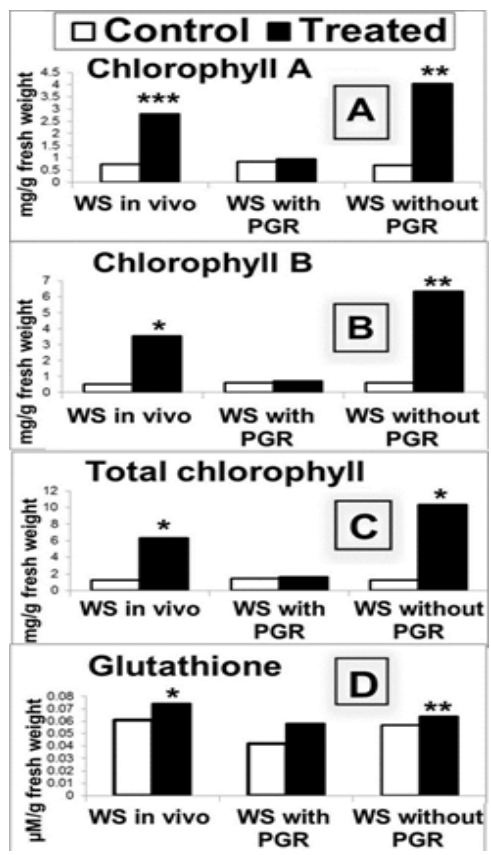

Figure 7: Chlorophyll and glutathione in control and treated WS samples in vivo and when grown in vitro on media with and without PGR. Asterisks indicate significant results. $(*: \mathrm{p}<0.05 ; * *$ : $\mathrm{p}<0.0005 ; * * *$ : $<0.0001, \mathrm{n}=2)$ 
Glutathione (Figure $7 \mathrm{D}$ ) was also found to be consistently higher in treated plants over controls, and significant in vivo as well as in vitro in absence of PGR (significance shown in the figure). Glutathione acts as a reducing agent for reactive oxygen species, hence higher levels in steady state conditions would normally indicate a higher ability to cope with stress related increases in ROS. The beginning of a stress event can also cause rise in glutathione levels and further testing for its oxidized forms is necessary for any assessment of the existing stress levels. The consistent increase, with a more significant increases in vivo in presence of pests and in vitro in absence of hormones are consistent with improvement in stress response and the differences seen during plant growth, confirming alterations at biochemical levels as a result of the treatment. Further investigation is necessary to determine their precise nature.

\section{Anticancer activity}

WS secondary metabolites are known to be involved in plant defences and adaptation, with proven antioxidant and antitumor properties. An increase in plant vitality may therefore be expected to result in increase of their levels, and of their medicinal bioactivity. Extracts of WS leaves containing their major metabolites were tested for anticancer activity against liver cancer cells, HepG2, using MTT assays.

While all extracts displayed cytotoxic effect, a small but consistent increase in toxicity $(2.23 \%$ to $6.99 \%)$ was seen in extracts from treated over untreated plants (Figure $8 \mathrm{~A}-\mathrm{B}$ ). Viability of cancer cells decreased with higher concentrations of WS extract, and was in each case lower with extracts from treated plants, with the increase in toxicity also larger for higher concentrations of extract. Extracts from in vivo treated plants showed the highest anti-cancer activity, followed by in vivo controls. Treated plants in vitro grown in presence of PGR were next on the scale, while treated plants in absence of PGR showed activity almost identical to that of controls in presence of PGR (not tested for significance). Extracts from controls in vitro grown in absence of PGR consistently showed minimum toxicity, while the anticancer toxicity was in this case synergistically more in the case of plants with an improved hormonal environment during development as compared to a deprived one.

A representative case of cancer cells may be seen in Figure $8 \mathrm{~B}$, with a greater toxic effect seen using treated compared to untreated plants.

HPLC analysis showed increase in levels of WS secondary metabolites, Withaferin A and Withanolide $\mathrm{D}$, in treated plants (Figure $8 \mathrm{C}$ ), up to $48 \%$ for Withaferin $\mathrm{A}$ and $21 \%$ for Withanolide D. These are Withanolides from the class of steroidal lactones, and have been found to use a variety of mechanisms targeting cancerous cells, such as induction of apoptosis, arrest of cell life cycle, inhibition of proliferation and antiangiogenic activity via many different mechanisms at the molecular levels. Thus an increase in the Withanolides can partially or wholly account for the effect seen above.

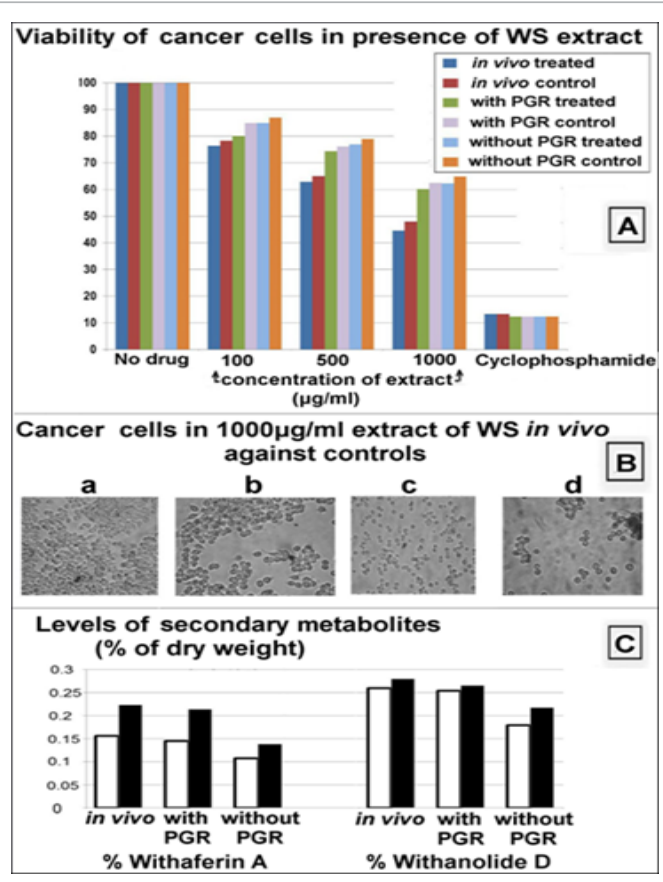

Figure 8: WS anti-cancer activity (A) Viability of liver cancer cells, HepG2, in differing concentrations $(100 \mu \mathrm{g} / \mathrm{ml}, 500 \mu \mathrm{g} / \mathrm{ml}, 1000 \mu \mathrm{g} / \mathrm{ml})$ of ethyl acetate extract of in vivo WS and WS grown in vitro with and without PGR, when compared against controls with no drug additives and against positive controls having the anti-cancer drug, cyclophosphamide. Extracts from treated plants displayed higher toxicity as compared to extracts from corresponding untreated control plants. Across groups, treated WS in vivo had maximum anti-cancer effect, while untreated (control) WS grown in vitro without PGR showed minimum toxicity to cancer cells (B) Cancer cells in presence of (a) no additives (b) $1000 \mu \mathrm{g} / \mathrm{ml}$ extract of untreated WS in vivo (c) $1000 \mu \mathrm{g} / \mathrm{ml}$ extract of treated WS in vivo (d) the anti-cancer drug cyclophosphamide (C) Levels of metabolites with proven anti-cancer cell activity in control and treated WS grown in vivo and in vitro with and without PGR

\section{DNA polymorphism testing using RAPD analysis}

Plants exhibit a high degree of phenotypic plasticity in response to environmental conditions and display capacity for quicker change in DNA in adaptive responses as compared to the larger animals. Adaptive changes on an organism-wide scale, including visible morphological changes, indicate the possibility of genetic changes. If biofield energies are found to influence genetic processes in more directed ways, their influence could perhaps have increased as the complexity of evolving life increased.

DNA fingerprinting using RAPD analysis with five primers was carried out on 5 leaf samples each from untreated and treated WS plants, DNA profiles being compared separately within each of the control and treated groups and across the two groups.

In the case of in vitro cultures, high genetic variability was found within both control and treated groups, hence genetic impact of the biofield treatment could not be determined. Somaclonal variants are known to occur in such cases and this model was not suitable for determining genetic impact.

The results from in vivo plants are presented in Supplementary Figure S1 and the banding patterns are summarized in Supplementary Table S2. Although banding patterns were different between control and treated plants, the variations were much less when each group was compared within itself. The analysis of the pooled data using Popgene software showed $6.56 \%$ polymorphic loci within each of the control as well as treated groups, whereas across control and treated groups the percentage of polymorphic loci was $77.05 \%$. 
Biofeild treatment on plant growth

Supplementary Table S2. DNA polymorphism in W. somnifera in vivo within and between controls \& treated plants.

\begin{tabular}{|c|c|c|c|c|c|c|c|c|c|c|}
\hline \multirow[b]{2}{*}{ Primer } & \multirow{2}{*}{$\begin{array}{l}\text { Nucleotide se- } \\
\text { quence }\left(5^{\prime}-3{ }^{\prime}\right)\end{array}$} & \multicolumn{3}{|c|}{ Controls } & \multicolumn{3}{|c|}{ Treated } & \multicolumn{3}{|c|}{ Pooled control and treated groups } \\
\hline & & $\begin{array}{l}\text { Monomor- } \\
\text { phic bands }\end{array}$ & $\begin{array}{l}\text { Polymorphic } \\
\text { bands }\end{array}$ & Total bands & $\begin{array}{l}\text { Monomor- } \\
\text { phic bands }\end{array}$ & $\begin{array}{l}\text { Polymor- } \\
\text { phic bands }\end{array}$ & $\begin{array}{c}\mathrm{T} \text { o t a } 1 \\
\text { bands }\end{array}$ & $\begin{array}{l}\text { Monomor- } \\
\text { phic bands }\end{array}$ & $\begin{array}{l}\text { Polymorphic } \\
\text { bands }\end{array}$ & $\begin{array}{c}\text { To t a } 1 \\
\text { bands }\end{array}$ \\
\hline OPA 9 & GGGTAACGCC & 5 & 0 & 5 & 7 & 0 & 7 & 2 & 8 & 10 \\
\hline OPA 10 & GTGATCGCAG & 8 & 0 & 8 & 8 & 0 & 8 & 3 & 10 & 13 \\
\hline OPB 4 & GGACTGGAGT & 8 & 0 & 8 & 4 & 4 & 8 & 1 & 14 & 15 \\
\hline OPB 12 & CCTTGACGCA & 5 & 4 & 9 & 7 & 0 & 7 & 4 & 5 & 9 \\
\hline OPC 7 & GTCCCGACGA & 8 & 0 & 8 & 10 & 0 & 10 & 4 & 10 & 14 \\
\hline
\end{tabular}

Table 2 shows the genetic identity matrix output of the software. Within the control group, the genetic identity varied from 0.93 to 1 , while the variation within the treated group was 0.96 to 1 . Across groups the genetic identity varies between 0.25 and 0.33 . Thus the increase in plant vitality caused by the non contact biofield treatment indicated improved adaptive ability and changes up to the genetic level.

Table 2. Nei's unbiased measures of genetic identity.

\begin{tabular}{|c|c|c|c|c|c|c|c|c|c|c|}
\hline & $\mathrm{C} 1$ & $\mathrm{C} 2$ & $\mathrm{C} 3$ & $\mathrm{C} 4$ & C5 & $\mathrm{T} 1$ & $\mathrm{~T} 2$ & $\mathrm{~T} 3$ & $\mathrm{~T} 4$ & T5 \\
\hline $\mathrm{C} 1$ & - & 1.000 & 0.934 & 0.934 & 0.934 & 0.295 & 0.279 & 0.246 & 0.246 & 0.246 \\
\hline $\mathrm{C} 2$ & & - & 0.934 & 0.934 & 0.934 & 0.295 & 0.279 & 0.246 & 0.246 & 0.246 \\
\hline $\mathrm{C} 3$ & & & - & 1.000 & 1.000 & 0.328 & 0.312 & 0.279 & 0.279 & 0.279 \\
\hline $\mathrm{C} 4$ & & & & - & 1.000 & 0.328 & 0.312 & 0.279 & 0.279 & 0.279 \\
\hline $\mathrm{C} 5$ & & & & & - & 0.328 & 0.312 & 0.279 & 0.279 & 0.279 \\
\hline $\mathrm{T} 1$ & & & & & & - & 0.960 & 0.960 & 0.960 & 0.960 \\
\hline $\mathrm{T} 2$ & & & & & & & - & 0.970 & 0.970 & 0.970 \\
\hline $\mathrm{T} 3$ & & & & & & & & - & 1.000 & 1.000 \\
\hline $\mathrm{T} 4$ & & & & & & & & & - & 1.000 \\
\hline T5 & & & & & & & & & & - \\
\hline
\end{tabular}

C1-C5: controls; T1-T5: treated samples

OPA 9
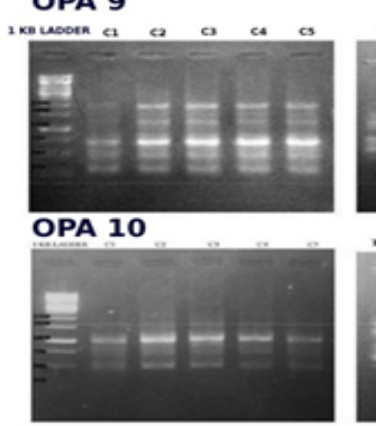

OPB 4

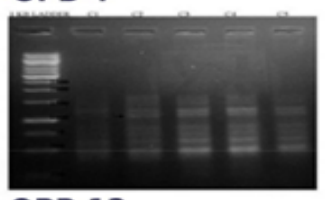

OPB 12

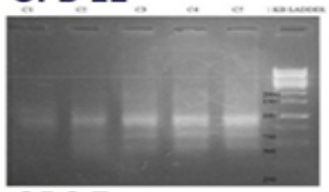

OPC 7

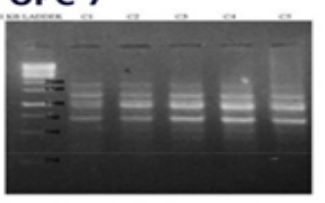

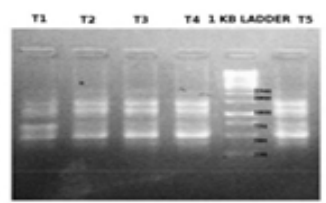
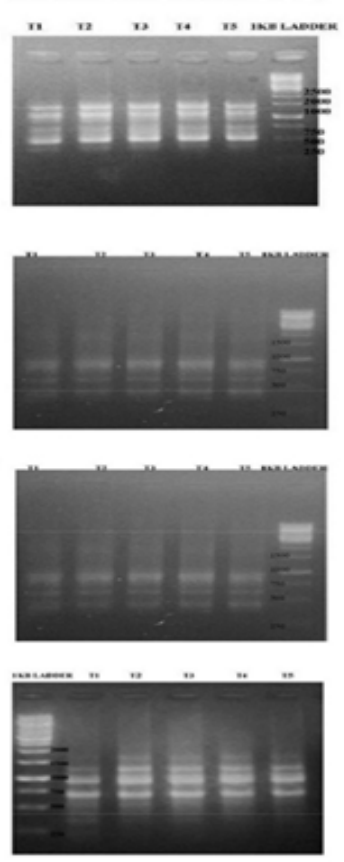

Supplementary Figure S1. RAPD Analysis of W. somnifera wild plant with 5 primers. Top to Bottom: OPA9, OPA10, OPB4, OPB12, OPC7. Lanes from left to right are Controls $\mathrm{C} 1-\mathrm{C} 5$ and treated samples $\mathrm{T} 1-\mathrm{T} 5$.

\section{Discussion}

The enhanced scale and consistency of results seen here across multiple kinds of samples and experiments indicate the efficacy of biofield energies. Formal rigorous testing by science has indicated the existence of fundamental laws, which hold within material fields as well as biofield energies, while scientific methodology has often been based on the assumption that the material events are the primary ones. The assumption is not however a necessary one for its results to hold and the results in the current case indicate that the same laws may also be approached from the viewpoint of vital energies in the biofield. Material and biofield energies appear to be inter convertible, complementary aspects of the same phenomenon, accessible to manipulation from either side. While much is achievable through an interaction of material energies and structures, the results suggest that biofield energies may interact sufficiently with material ones to make absolute control of events impossible through material means alone, with a need to further investigate the nature of the primary energies within such information-based events.

The results indicate a potential for significant reciprocal influence of biofield energies on material fields and the availability of a paradigm for objective testing in areas, which were earlier not believed to be within the domain of scientific methodology.

An identification of the laws, which hold at these levels, may make it easier to improve synergies of results and development of technologies in closer coordination with vital energies. 


\section{Acknowledgements}

This work was supported by the Trivedi Foundation and the experiments were carried out by Biozone Research Technologies, Chennai, India.

\section{Abbreviations}

PGR: Plant growth regulators; WS: Withania somnifera; AD: Amaranthus dubius.

\section{Reference}

1. Dunne, B.J., Jahn, R.G. Consciousness, information, and living systems. (2005) Cell Mol Biol 51: 703-714.

2. Trivedi, M.K., Tallapragada, R.M. A transcendental to changing metal powder characteristics. (2008) Metal Powder Rep 63(9): 22-28, 31.

3. Trivedi, M.K., Patil, S. Impact of an external energy on Yersinia enterocolitica [ATCC -23715] in relation to antibiotic susceptibility and biochemical reactions: An experimental study. (2008) The Internet Journal of Alternative Medicine. 6(2)

4. Trivedi, M.K., Bhardwaj, Y., Patil, S., et al. Impact of an external energy on Enterococcus faecalis [ATCC - 51299] in relation to antibiotic susceptibility and biochemical reactions - An experimental study. (2009) J Accord Integrative Medicine 5(2): 119-130.

5. Dabhade, V.V., Trivedi, M.K., Tallapragada, R.M. Effect of external energy on the atomic, crystalline, and powder characteristics of antimony and bismuth powders. (2009) Bull Mater Sci 32(5): 471-479.

6. Trivedi, M.K., Tallapragada, R.M. Effect of superconsciousness external energy on atomic, crystalline and powder characteristics of carbon allotrope powders. (2009) Mater Res Innovat 13(4): 473-480.

7. Trivedi, M.K., Patil, S., Tallapragada, R.M. Effect of bio field treatment on the physical and thermal characteristics of vanadium pentoxide powders. (2013) J Mater Sci Eng S11: 001.

8. Trivedi, M.K., Patil, S.,Tallapragada, R.M. Effect of bio field treatment on the physical and thermal characteristics of Silicon, Tin and Lead powders. (2013) J Material Sci Eng 2: 125.

9. Trivedi, M.K., Patil, S.,Tallapragada, R.M. Atomic, Crystalline and Powder Characteristics of Treated Zirconia and Silica Powders (2014) J Material Sci Eng 3: 144

10. Patil, S.A., Nayak, G.B., Barve, S.S., et al. Impact of biofield treatment on growth and anatomical characteristics of Pogostemon cablin (Benth). (2012) Biotechnology 11(3): 154-162.

11. Rubik, B. The biofield hypothesis: its biophysical basis and role in medicine. (2002) J Altern Compl Med. 8(6): 703-717.

12. Lenssen, A.W. Biofield and fungicide seed treatment influences on soybean productivity, seed quality and weed community. (2013) Agric J 8(3): 138-143.

13. Shinde, V., Sances, F., Patil, S., et al. Impact of biofield treatment on growth and yield of lettuce and tomato. (2012) Aus J Basic Appl Sci 6(10): 100-105.
14. Sances, F., Flora, E., Patil, S., et al. Impact of Biofield Treatment On Ginseng And Organic Blueberry Yield. (2013) AGRIVITA, Journal of Agricultural Science 35(1)

15. Trivedi, M.K., Patil, S. Impact of an external energy on Staphylococcus epidermis [ATCC -13518 ] in relation to antibiotic susceptibility and biochemical reactions - An experimental study. (2008) Journal of Accord Integrative Medicine 4(4): 230-235.

16. Engel, G.S., Calhoun, T.R., Read, E.L., et al. Evidence for wavelike energy transfer through quantum coherence in photosynthetic systems. (2007) Nature 446: 782-786.

17. Gauger, E.M., Rieper, E., Morton, J.L., et al. Sustained quantum coherence and entanglement in the avian compass. (2011) Phys Rev Lett 106: 4.

18. Van der Velden, H.A. The number of quanta necessary for the perception of light in the human eye. (1946) Opthalmologica 111(6): 321331.

19. Turin, L. A spectroscopic mechanism for primary olfactory reception. (1996) Chem Senses 21(6): 773-791.

20. Brookes, J.C., Hartoutsiou, F., Horsfield, A.P., et al. Could humans recognize odor by phonon assisted tunneling? (2007) Phys Rev Lett 98(3): 038101.

21. Arndt, M., Juffmann, T., Vedral, V. Quantum physics meets biology. (2009) HFSP Journal 3: 386-400

22. Stapp, H.P. Mindful Universe: Quantum Mechanics and the participating observer. (2007) Springer, Heidelberg, New York.

23. Schrödinger, E. What is Life? (1944) Cambridge: Cambridge University Press

24. Mir, B.A., Khazir, J., Mir, N.A., et al. Botanical, chemical and pharmacological review of Withania somnifera (Indian ginseng): an Ayurvedic medicinal plant. (2012) Indian J Drugs Dis 1(6): 147-160.

25. Szarc vel Szic, K., Op de Beeck, K., Ratman, D., et al. Pharmacological levels of Withaferin A (Withania somnifera) trigger clinically relevant anticancer effects specific to triple negative breast cancer cells. (2014) PLoS One 9: e87850.

26. Murashige, T., Skoog, F. A revised medium for rapid growth and bioassays with tobacco tissue cultures. (1962) Physiol Plant 15(3): 473497.

27. Arnon, D.I. Copper enzymes in isolated chloroplasts and polyphenol oxidase in Beta vulgaris. (1949) Plant Physiol 24(1): 1-15.

28. Moron, M.S., Depierre, J.W., Mannervik, B. Levels of glutathione, glutathione reductase and glutathione S-transferase activities in rat lung and liver. (1979) Biochim Biophys Acta 582(1): 67-78.

29. Kang, B.K., Chon, S.K., Kim, S.H., et al. Controlled release of paclitaxel from microemulsion containing PLGA and evaluation of anti-tumor activity in vitro and in vivo. (2004) Int J Pharm 286(1-2): 147-156. 30. Doyle, J.J., Doyle, J.L. Isolation of plant DNA from fresh tissue. (1990) Focus 12: 13-15. 